\title{
Tightly spiral shaped bacteria in the human stomach: another cause of active chronic gastritis?
}

\author{
Arthur Morris, M Rafiq Ali, Lindy Thomsen, Brian Hollis
}

\begin{abstract}
Tightly spiral shaped Gram negative bacteria were seen in the gastric biopsies obtained from two patients undergoing gastroscopy. Active chronic gastritis was present in both patients and one patient also had gastric ulceration. Attempts to culture the organism by a number of methods were unsuccessful but positive urease results were obtained in both patients. Both patients were treated with colloidal bismuth subcitrate. Biopsies taken after treatment showed resolution of infection and histological gastritis. These results suggest that Helicobacter pylori is not the only organism associated with chronic active gastritis in man.
\end{abstract}

In 1983 Dr J Warren reported an association between the presence of curved bacilli in gastric biopsies and the presence of active chronic gastritis. ' We now know a great deal about this organism, currently named Helicobacter pylori. ${ }^{2}$ Human ingestion studies have shown that $H$ pylori is a cause of active chronic gastritis. ${ }^{34}$ Infection is found world wide with approximately $50 \%$ of patients presenting for upper gastrointestinal tract endoscopy for the investigation of dyspepsia being infected with this organism. ${ }^{5}$

$H$ pylori may not, however, be the only organism capable of colonising the human stomach. McNulty et al reported seeing spiral organisms morphologically distinct from $H$ pylori in the antral biopsies of six patients in a series of 1650 patients presenting for upper gastrointestinal endoscopy. ${ }^{6}$ We have observed similar organisms in the antral biopsies of two patients presenting for endoscopy at this hospital. We present here our findings in these patients as well as their positive response to colloidal bismuth subcitrate treatment. The results suggest that these organisms may cause active chronic gastritis in man.

\section{Methods}

Gastroenterology,

Middlemore Hospital,

Otahuhu, Auckland, New

Zealand

M Rafiq Ali

Department of Medicine, Auckland Medical

School, Auckland, New

Zealand

Lindy Thomsen

Correspondence to: Dr A

Morris, Microbiology

Laboratory, Auckland

Hospital, Auckland 1, New

Zealand

Accepted for publication 22 May 1989 biology, and one for the CLO-test (Delta-West Perth, Western Australia) to detect the presen of urease. ${ }^{7}$ Transport and processing of biopsies for histology and microbiology were as previously published. ${ }^{8-11}$ Briefly, biopsies for histology were transported in $10 \%$ formol buffered saline and routinely processed for haematoxylin and eosin (H \& E), and Giemsa stained sections. Biopsies for microbiological evaluation were transported to the laboratory in $12.5 \%$ dextrose where both biopsies were placed on a clean glass slide in a drop of transport fluid and finely minced with sterile scalpel blades ${ }^{8-9}$ Most of the tissue homogenate was picked up with a cotton wood swab and inoculated onto selective agar. ${ }^{9}$ The remaining material was air dried, heat fixed, and Gram stained. Plates were incubated at $37^{\circ} \mathrm{C}$ in anaerobic jars evacuated to $520 \mathrm{mmHg}$ and flushed with a gas mixture of $10 \% \mathrm{CO}_{2}$ and $90 \%$ $\mathrm{N}_{2}{ }^{9}$ Plates were kept for a minimum of five days before discarding. Biopsy material taken at follow up from both patients was also inoculated onto lysed horse blood agar anaerobically and microaerophilically as above. Tissue homogenate was also inoculated into Bactec $8 \mathrm{~B}$ and $7 \mathrm{D}$ blood culture broths (Johnston Laboratories, Maryland) which were analysed daily for a week.

Follow up biopsies for histology and electron microscopy had the gastric mucus layer stabilised before transport in formol saline for histology or preparation for electron microscopy. For stabilisation, the mucosal surface of each biopsy was covered with heat inactivated rabbit serum, containing antibodies raised to human gastric mucus, and incubated at $4^{\circ} \mathrm{C}$ for one hour. Antibodies to human gastric mucus were prepared following methods for raising antibodies to rat colonic mucus. ${ }^{12}$ Specimens for electron microscopy were prepared by prefixing in a solution of $0.5 \%$ gluteraldehyde with $0.15 \%$ ruthenium red in $0 \cdot 1 \mathrm{M}$ cacodylate buffer $\mathrm{pH} 7 \cdot 4$ for 30 minutes at $20^{\circ} \mathrm{C}$ before fixation in $5 \%$ gluteraldehyde and $0.05 \%$ ruthenium red in $0 \cdot 1 \mathrm{M}$ cacodylate buffer $\mathrm{pH} 7 \cdot 4$. Biopsies were then routinely processed for transmission electron microscopy.

\section{Patient 1}

The patient, a 30 year old labourer, presented with an eight month history of intermittent moderate severe epigastric pain. The patient was prescribed Gaviscon (Reckitt and Colman), a gastric reflux suppressant, containing sodium alginate, sodium bicarbonate, and calcium carbonate, by his general practitioner. This produced significant relief but the pain returned when this agent was stopped and a second course of Gaviscon was ineffective.

At presentation the pain was described as being epigastric and worse at night and with food. He felt bloated after small amounts of food. There was no anorexia, vomiting, haematemesis, diarrhoea, melaena, or weight loss. He smoked 30 cigarettes a day and drank several pints of beer most nights. There was no other significant 


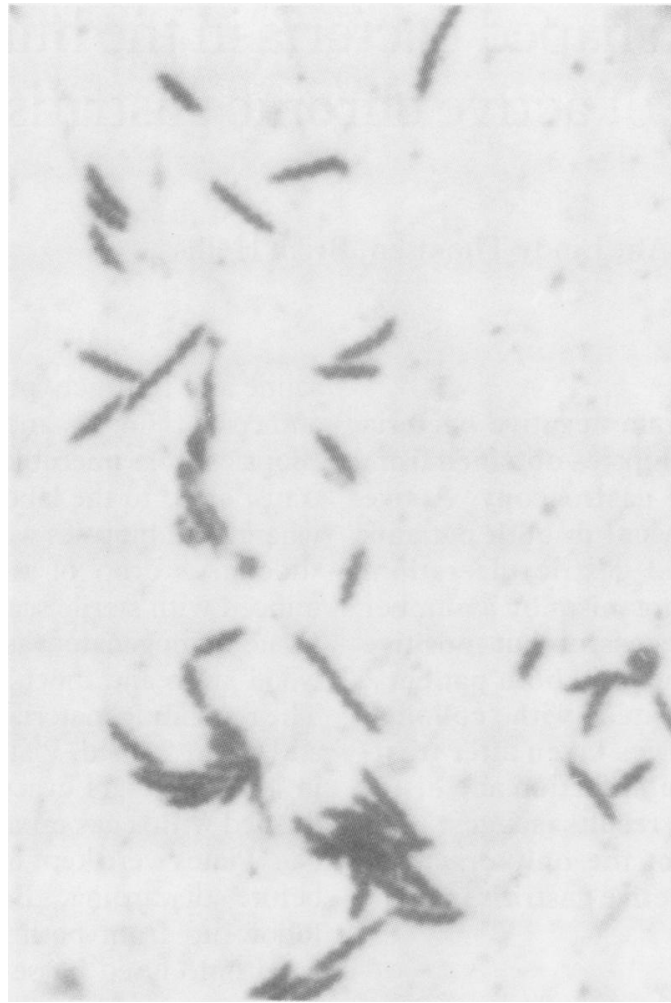

Figure 1: Gram stain of biopsy smear from patient 1. Long Gram negative tightly spiral, corkscrew, shaped organisms are shown. Oil immersion.

medical or family history. He had no contact with animals except for a dog obtained after the onset of his illness.

At endoscopy the oesophagus, stomach, and duodenum were normal. The Gram stained smear of the biopsy material revealed numerous Gram negative tightly spiralled organisms (Fig 1). Histology of the biopsies showed antral gastric mucosa with fragments of muscularis mucosae. The surface epithelium was intact but contained the occasional polymorphonuclear leukocyte. The lamina propria contained a mixed inflammatory cell infiltrate comprising of polymorphonuclear leucocytes, lymphocytes, and plasma cells which extended to the deeper glandular zone. Occasional gastric pits contained collections of polymorphonuclear leucocytes. Isolated spiral organisms were seen in the lumen of a few gastric pits in the Giemsa stained sections. There was no evidence of $H$ pylori infection by Gram stain, culture or histology and the patient was seronegative for $H$ pylori antibodies. ${ }^{13}$ The CLO-test was positive 24 hours after endoscopy.

The patient was recalled three weeks later. Endoscopy was again normal. Biopsies taken from the antrum and from the greater and lesser curves. Histology of the greater curve biopsies showed no gastritis but antral and lesser curve biopsies showed active chronic gastritis. Groups of spiral organisms were seen within the stabilised mucus of both antral and lesser curve biopsies (Figs 2 and 3). No organisms were seen associated with the gastric epithelium. No spiral organisms were recovered from the agar plates or the blood culture broth media. $H$ pylori was not seen or cultured.

The patient started a four week course of

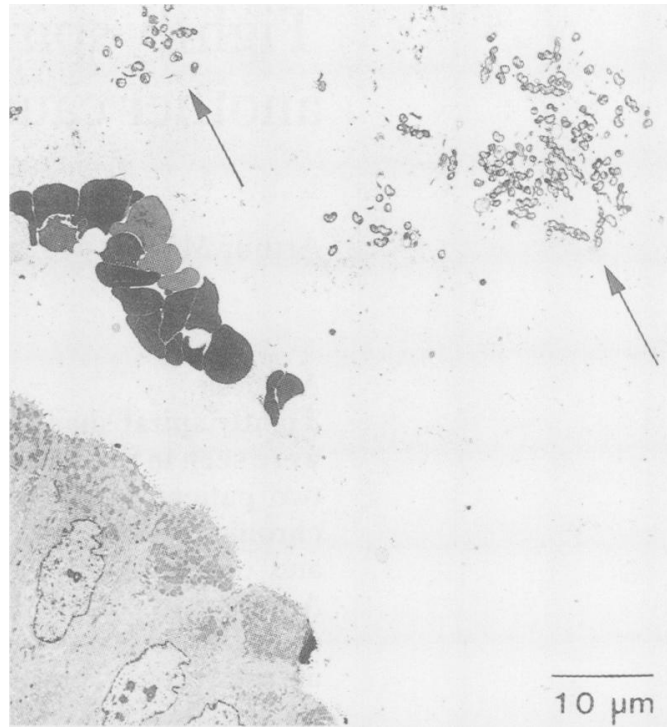

Figure 2: Transmission electron micrograph of an antral biopsy after stabilisation of gastric mucus. Groups of tightly spiral shaped organisms are present within the mucus, arrows. No organisms are associated with the gastric epithelium. Bar $=10 \mu \mathrm{m}$.

colloidal bismuth subcitrate (CBS, De-Nol, Gist Brocades, Delft, The Netherlands) tablets, two twice a day (bid). The patient was instructed to take the tablets on an empty stomach and not to eat or drink for an hour afterwards.

The patient was biopsied three days after finishing the course of colloidal bismuth subcitrate. His symptoms had resolved and endoscopy was normal. No spiral organisms were seen in the biopsy Gram stain or in the histology sections. The gastritis was almost resolved with only a mild increase in mononuclear cells but no polymorphonuclear leucocytes being present in any of the three areas biopsied - namely, antrum, greater and lesser curves of the body of the stomach.

The patient was seen again four weeks later where it was planned to obtain follow up biopsies after a period without colloidal bismuth sub-

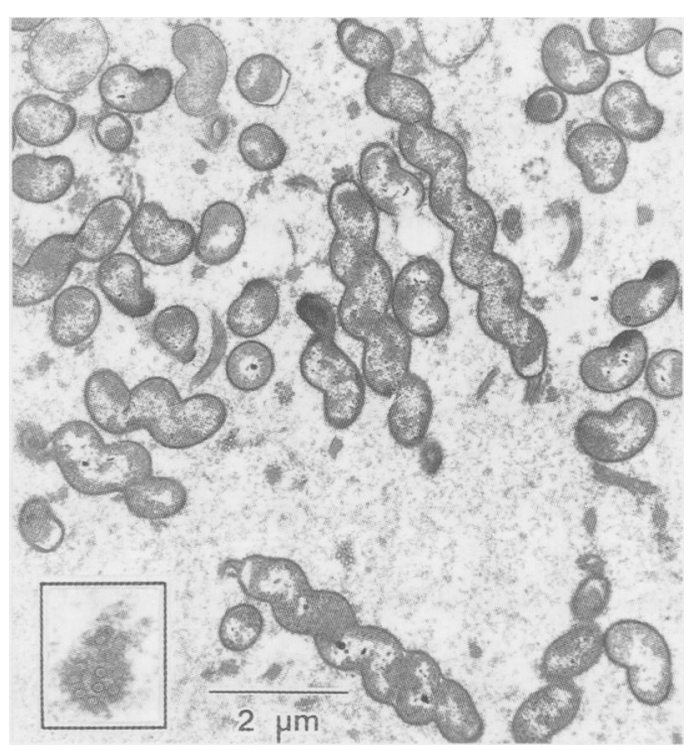

Figure 3: Transmission electron micrograph of tightly spiral, corkscrew, shaped organisms within the gastric mucus. Note the terminal position of the sheathed flagella. Bar $=2 \mu \mathrm{m}$. Inset shows high power of view of a tuft of flagella in cross
Interminal position of the sheathed flagella. Bar $=2 \mu \mathrm{m}$. Inset show.
section. 
citrate but the patient had attended his own medical practitioner because his pain had returned. He had been recommenced on colloidal bismuth subcitrate and had had his last colloidal bismuth subcitrate dose four days before this, his fourth visit. Endoscopy was normal and no organisms were seen in his biopsies. The histological gastritis had completely resolved.

The patient was rescoped 11 weeks later. During this time he was off all medication and had only experienced occasional episodes of epigastric discomfort upon waking. His endoscopy findings were normal. No organisms were seen in the Gram stain or in the histology sections and the CLO-test was negative at 24 hours. No gastritis was present in the three areas biopsied.

\section{Patient 2}

The patient, a 38 year old horse trainer, was admitted after a seven day history of colicky lower abdominal pain. Three days before admission he experienced epigastric pain and had episodes of vomiting and diarrhoea. On examination there was diffuse epigastric tenderness but no guarding or rebound. Rectal examination was normal. Upper abdominal ultrasound was normal. On the fourth hospital day endoscopy was performed. The oesophagus and duodenum were normal. In the stomach there was a $3 \mathrm{~mm}$ ulcer at the angulus and diffuse erythema with erosions in the antrum. The patient started colloidal bismuth subcitrate and cimetidine (Tagamet, Smith Kline \& French) and was discharged.

Gram stain of the biopsy smear revealed tightly spiral shaped organisms. Many organisms were also seen in the $\mathrm{H}$ and $\mathrm{E}$ and Giemsa stained histology sections. Nearly all organisms were seen within the mucus with only occasional organisms associated with the gastric epithelium. Histology showed moderate to severe active chronic gastritis. In many areas the inflammatory cell infiltrate was comprised almost entirely of polymorphonuclear leukocytes (Fig 4). Inflammation extended to the glandular zone of the mucosa. $H$ pylori was neither seen nor cultured. The CLO-test was positive 24 hours after endoscopy. When the results of the histology and microbiology were known the patient was contacted and the cimetidine was stopped. The patient was seronegative for $H$ pylori antibodies.

The patient was seen 10 days after completing a two month course of colloidal bismuth subcitrate, two swallow tablets bid. While taking colloidal bismuth subcitrate he had experienced only occasional mild epigastric pain and this was usually associated with bending over. For three days after stopping treatment he had episodes of epigastric discomfort, much milder than in his presenting illness but these had resolved by the time of endoscopy. Endoscopy to the second part of the duodenum was entirely normal. Histology showed resolution of the gastritis (Figs 5,6 ). No organisms were seen in the biopsy Gram stain or in the histology section.

The patient was rescoped five weeks later. His endoscopic findings were normal. No organisms were seen in the Gram stain or in the histology

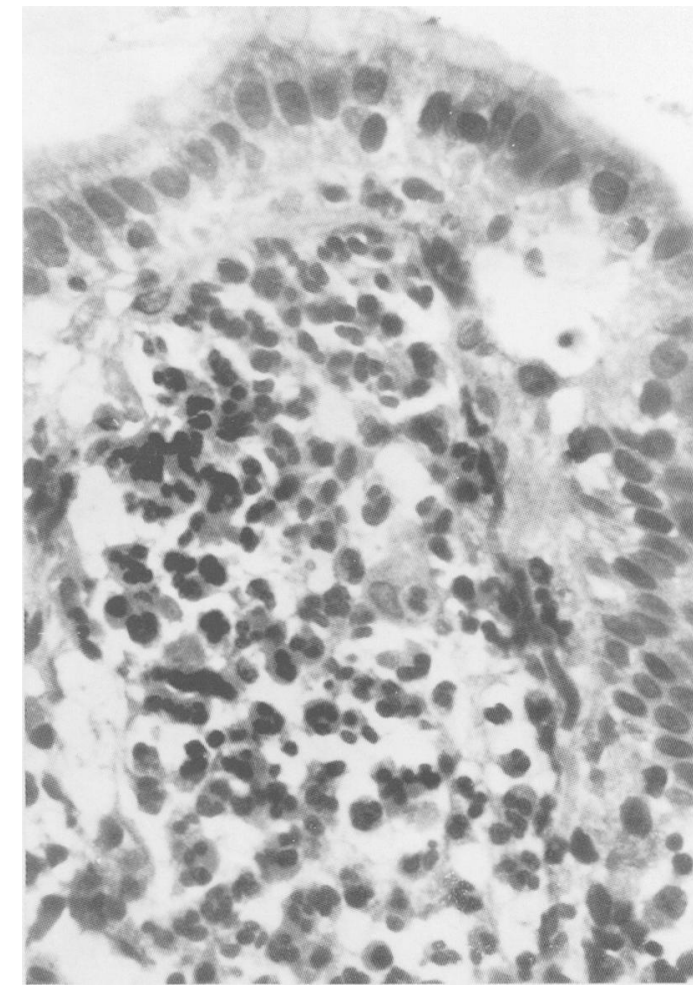

Figure 4: Antral biopsy from patient 2. The inflammatory cell infiltrate in the lamina propria is dominated by

polymorphonuclear leucocytes. Haematoxylin and eosin.

sections and the CLO-test was negative at 24 hours. No gastritis was present in the three areas biopsied.

\section{Discussion}

We have presented the clinical, endoscopic, and histological findings to two patients with their stomachs infected with a newly recognised tightly spiral or 'corkscrew' shaped Gram negative organism. In both patients both the antrum and body regions of the stomach were infected. Although we were unable to grow this organism others have cultured similar urease positive organisms from the stomachs of cats. ${ }^{14}$ is The positive CLO-test results in our patients suggest that the human 'corkscrew' shaped Gram negative organism is also urease positive. McNulty et al obtained only one positive urease result in their six patients. ${ }^{6}$ This difference may be the result of the numbers of organisms involved, both our patients were heavily infected. Alternatively the organism may not produce as much urease as $H$ pylori, in our experience similar numbers of $H$ pylori give positive CLO-test results with 30 minutes.

We do not know if the clinical presentations of our patients were related to their gastric infection. We include their clinical data so that it may be compared with that of other patients found to be infected with this organism. It may be difficult to acquire information about any clinical syndromes associated with the organism because of its rarity. McNulty et al encountered only six cases in a series of 1650 patients $^{6}$ and we have only seen two cases in over 700 Auckland patients biopsied to detect $H$ pylori. ${ }^{8-11}$

Routine processing of gastric biopsies for histology or electron microscopy results in con- 


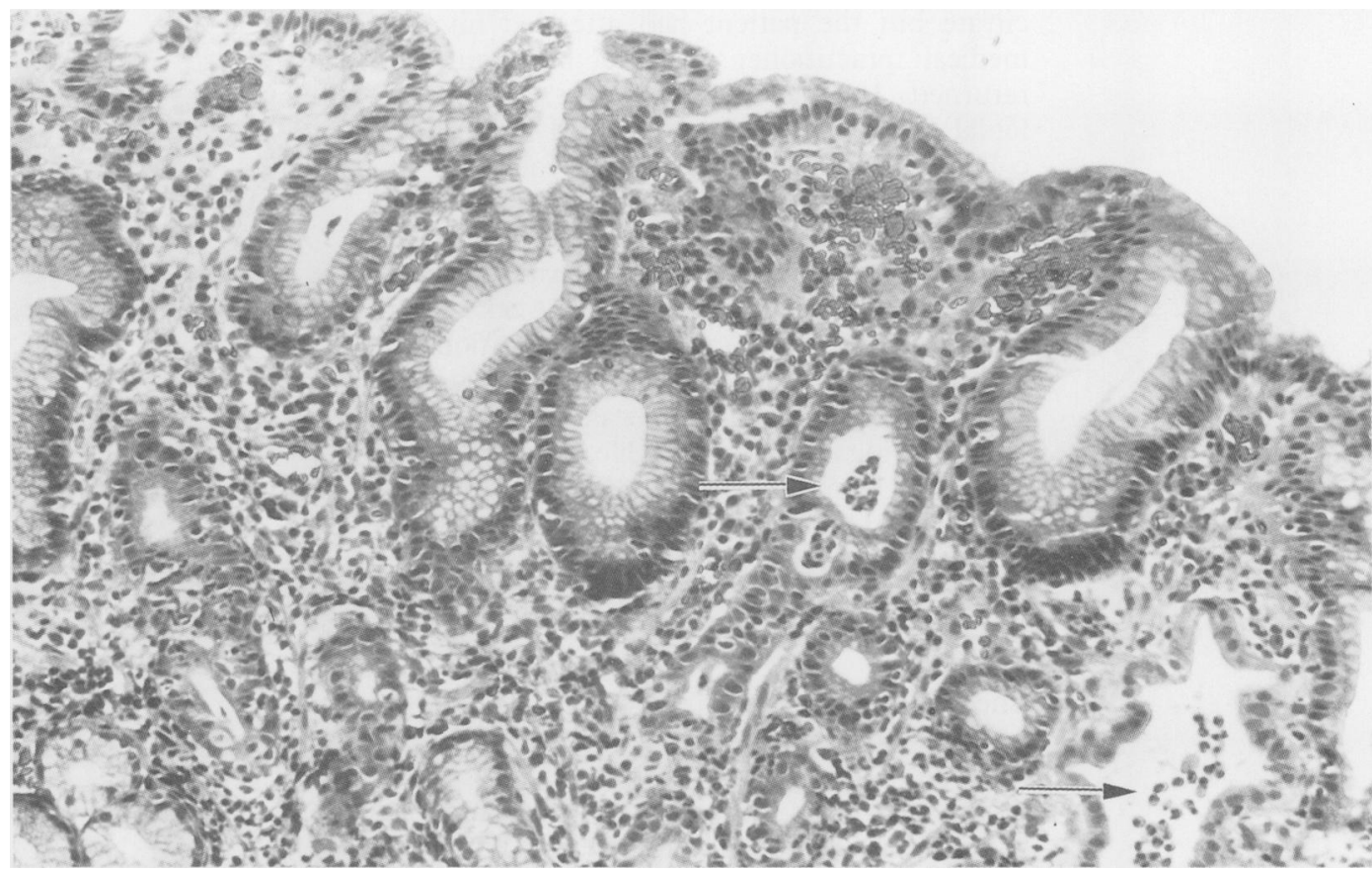

Figure 5: Antral biopsy from patient 2 before colloidal bismuth treatment. There is a moderately intense mixed inflammatory cell infiltrate within the lamina propria. Polymorphonuclear leucocytes are present within the gastric epithelium and also in the lumen of gastric pits, arrows. Haematoxylin and eosin.

traction and often the loss of the gastric mucus layer. Stabilisation of gastric mucus may permit a better determination of the distribution of organisms within gastric mucus by preventing or minimising the artifacts caused by routine processing. ${ }^{16}$ We attempted to stabilise the gastric mucus with rabbit antibodies raised against human gastric mucus. In patient 1 , many more bacteria were seen in biopsies after mucus stabilisation than in those routinely processed. Nearly all the organisms in our patients were located within the mucus layer. In both patients only the occasional organism was seen closely associated with the gastric epithelium in $\mathrm{H}$ and $\mathrm{E}$ stained sections, and this could have been caused by the processing artifact. McNulty et al showed organisms within the lumen of a pit with no close association with the epithelium. ${ }^{6}$ It is possible therefore that this organism is more a 'mucus dweller' than an 'epithelial coloniser'. Curry et al have observed similar tightly spiralled shaped bacteria in baboon stomachs not only within the mucus layer at the base of crypts but also within the canaliculi of parietal cells. ${ }^{17}$

In both patients colloidal bismuth subcitrate treatment resulted in apparent eradication of infection and complete resolution of the histological gastritis. Neither patient had relapsed at longterm follow up, 11 and 5 weeks after their last dose of colloidal bismuth subcitrate respect-

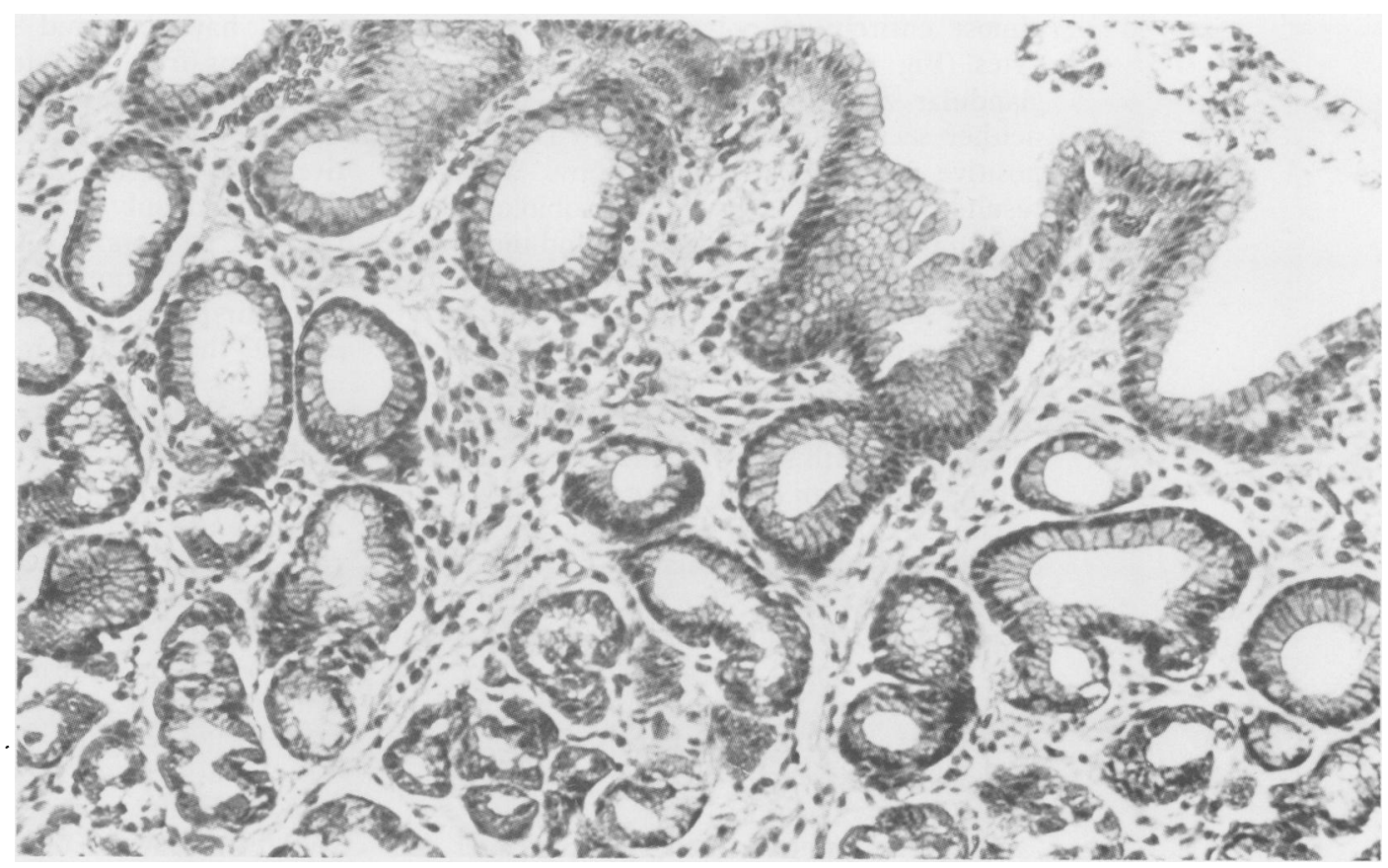

Figure 6: Antral biopsy from patient 2, 10 days after a two month course of colloidal bismuth. The histological gastritis has resolved. Haematoxylin and eosin. 
ively. After colloidal bismuth subcitrate treatment of $H$ pylori infection $88 \%$ of patients clear of infection four weeks after treatment remain clear at one year.$^{18}$ If this new organism behaves like $H$ pylori then both patients are probably cured. We believe the response to colloidal bismuth subcitrate treatment is strong evidence implicating this organism as a cause of active chronic gastritis. All six patients described by McNulty et al had active chronic gastritis but their response to treatment has not yet been published.

The stomachs of many mammalian species including man harbour spiral shaped organisms. ${ }^{161+151719-22}$ In 1939 Doenges observed long organisms with six to eight twists per organism in the stomachs of Rhesus monkeys. ${ }^{22}$ He also observed four morphologically distinct spiral organisms in the stomach of man and one type, although seen in only two human stomachs, was $6 \mu \mathrm{m}$ in length, $0.75 \mu \mathrm{m}$ in diameter and had six to eight spirals per cell. ${ }^{22}$ From the morphological description and the photograph of the organisms seen in the monkey stomach it is most probable that Doenges was describing the organism reported here and by McNulty et al. ${ }^{6}$ Cats and dogs harbour spiral organisms which are morphologically similar to the organisms seen in our patients ${ }^{1+151920}$ raising the possibility that human infection may be from an animal source. Testing of this possibility must await comparison of animal and human organisms after their successful culture.

It would appear that Helicobacter pylori is not the only organism capable of colonising the human stomach. Tightly spiralled, 'corkscrew', shaped Gram negative bacteria are associated with active chronic gastritis and, like $H$ pylori, they may be found in stomachs with peptic ulceration. Both infection and histological gastritis resolved with colloidal bismuth subcitrate treatment suggesting that the organisms may cause histological active chronic gastritis. The authors wish to thank Mr Mark Vanderwee, Department of
Experimental Pathology, Pathology Department, Auckland Experimental Pathology, Pathology Department, Auckland
Medical School for the electron microscopy, and the Photographic
Departments of the Auckland Medical School and Auckland Hospital for the preparation of the figures. L Thomsen is supported by the Ruth Spencer Medical Research Trust.

1 Warren JR. Unidentified curved bacilli on gastric epithelium in active chronic gastritis. Lancet 1983; i: 1273

2 Goodwin C, Armstrong J, Chilvers T, et al. Transfer of Campylobacter pylori and Campylobacter mustelae to Helicobacter gen nov as Helicobacter pylori comb nov and Helicobacter mustelae comb nov, respectively. Int $\mathcal{F}$ Syst Bacterio 1989; 39: 397-405.

3 Marshall B, Armstrong J, McGechie D, Glancy R. Attempt to fulfill Kock's postulates for pyloric Campylobacter. Med $\mathcal{J}$ Aust 1985; 142: 436-9.

4 Morris A, Nicholson G. Ingestion of Campylobacter pyloridis causes gastritis and raised fasting $\mathrm{pH}$. Am $\mathcal{f}$ Gastroenterol 1987; 82: 192-9.

5 Blaser M. Gastric Campylobacter-like organisms, gastritis and peptic ulcer disease. Gastroenterology 1987; 93: 371-83.

McNulty C, Dent J, Curry A, et al. New spiral bacterium in gastric mucosa. F Clin Pathol 1989; 42: 585-91.

7 Marshall B, Warren J, Francis G, Langton S, Goodwin C, Blincow E. Rapid urease test in the management of Campylobacter pyloridis-associated gastritis. Am f Gastroenterol 1987 82: 200-10.

8 Morris A, Gillies M, Paton K. Detection of Campylobacter pyloridis. NZ Med f 1986; 99: 336.

9 Morris A, Arthur J, Nicholson G. Campylobacter pyloridi infection in Auckland patients with gastritis. NZ Med $\mathcal{J}$ 1986; 99: 353-55.

10 Morris A, McIntyre D, Rose T, Nicholson G. Rapid diagnosis of Campylobacter pyloridis infection. Lancet 1986; i: 49.

11 Morris A, Ali R, Brown P, Lane M, Palmer R. Treatment of Campylobacter pylori gastritis; a pilot study, using Pirenzipine dihydrochloride (Gastrozepin) and three formulations of Colloidal bismuth substrate (De-Nol). NZ Med f 1988; 101 : $651-4$.

12 Bollard J, Vanderwee M, Smith G, Tasman-Jones C, Gavin J, Lee S. Preservation of mucus in situ in rat colon. Dig Dig Sci 1986; 31: $1338-44$

13 Morris A, Nicholson G, Lloyd G, Haines D, Rogers A, Taylor D. Seroepidemiology of Campylobacter pylori. NZ Med $\mathcal{F}$ 1986; 99: 657-9.

14 Lee A, Dent J, Hazell S, McNulty C. Origin of spira organisms in human gastric antrum. Lancet 1987; i: $300-1$.

15 Lee A, Hazell S, O'Rouke J, Kouprach S. Isolation of a spiralshaped bacterium from the cat stomach. Infect Immun 1988 56: $2843-50$.

16 Bollard JE, Vanderwee M, Smith EW, Tasman-Jones C, Gavin JB, Lee SP. Location of bacteria in the mid-colon of the rat. Appl Environ Microbiol 1986; 51: 604-8.

17 Curry A, Jones D, Eldridge J. Spiral organisms in the baboon stomach. Lancet 1987; ii: 634-5.

18 Rauws R, Langenberg W, Houghoff H, Zanen H, Tytgat G. Campylobacter pyloridis-associated chronic active antral gastritis. A prospective study of its prevalence and the effects gastritis. A prospective study of its prevalence and the effects of antibacterial

19 Lee A, Hazell S. Campylobacter pylori in health and disease: an ecological perspective. Microbiol Ecology Health Dis 1988; 1 1-16.

20 Weber A, Schmittdiel E. Electron microscopic and bacteriologic studies of Spirella isolated from the fundic stomachs of cats and dogs. Am F Vet Res 1962; 23: 422-7.

21 Freedberg A, Barron L. The presence of spirochetes in human gastric mucosa. Am f Dig 1940; 27: 443-5.

22 Doenges J. Spirochetes in the gastric glands of Macacus rhesus and man without related disease. Arch Pathol 1939; 27: 469- 